\title{
Retinoblastoma cT4b TNM Finding v7
}

National Cancer Institute

\section{Source}

National Cancer Institute. Retinoblastoma cT 4b TNM Finding v7. NCI Thesaurus. Code C88766.

Invasion into the orbit. (from AJCC 7th Ed.) 